\title{
Endodontic treatment of a mandibular first molar with radix entomolaris: A case series
}

\author{
Harakh Chand Baranwal ${ }^{1, *}$, Neeraj Kumar', Nidhi Singh ${ }^{3}$, Ankita Singh ${ }^{4}$ \\ ${ }^{1}$ Professor, ${ }^{2,4} \mathrm{Junior}$ Resident, ${ }^{3}$ Senior Resident, ${ }^{1,3}$ Dept. of Conservative Dentistry \& Endodontics, Faculty of Dental Sciences, ${ }^{1-}$ \\ ${ }^{3}$ Institute of Medical Sciences, Banaras Hindu University, Varanasi, Uttar Pradesh, India \\ *Corresponding Author: \\ Email: neerajbhu@ gmail.com
}

\begin{abstract}
Aim: A complete knowledge on the root canal anatomy and morphology is a basic prerequisite for the successful endodontic treatment. Successful endodontic treatment depends on locate all the canals and proper chemomechanical preparation followed by obturation with proper hermetic seal. Failure may occur due to incomplete knowledge and unusual tooth morphology. Mandibular molars may have an extra root when located lingually called radix entomolaris or buccally called radix paramolaris. The successful treatment depend upon the complete Knowledge abnormal root canal morphology. Case Reports: in this article describe three cases of multirooted mandibular first molar and their successful endodontic treatment.

Conclusions: For successful endodontic treatment A clinician should have complete knowledge of normal and abnormal anatomy of mandibular first molar and as well as use of recent tool of endodontics like computed tomography and the operating microscope
\end{abstract}

Key words: Endodontic treatment, Radix entomolaris.

\section{Introduction}

The complete success of treatment depends on locate all canals, complete debride the canal and seal completely with a root filling material. In the literature Carabelli first reported extra root in molar is called radix entomolaris. ${ }^{1}$ Three roots rarely found in mandibular molar and its frequency is $5 \%$ in Indian populations. ${ }^{2}$ Abnormal tooth morphology with extra root are identified by complete knowledge of normal tooth morphology was described by Carlsen and Alexandersen. ${ }^{3}$ This article describe the case of teeth have three roots and contain the four canal in a mandibular first molar.

\section{Case Reports}

\section{Case 1}

A 36-year-old male was referred to the endodontic department with a complaint of food lodgement and pain in right back posterior region for 1 year. Intermittent pain is present. Clinical examination of right mandibular molar revealed a carious lesion [Fig. 1] and show tenderness on percussion. The health of periodontal ligament of 36 was normal. Teeth are non-vital on doing vitality test. Radiographic examination of 46 showed a radiolucency overlapping pulp chamber and periapical radiolucency are also present on the mesial root [Fig. 2]. Additional radiolucent outline of PDL is present. On the examination, the diagnosis was made which is asymptomatic irreversible pulpitis. Local anesthesia was performed. The tooth was isolated by a rubber dam. Caries was removed and endo access bur was used for access opening. On examination of access cavity by DG 16 explorer show four canals i.e, one distal and two mesial canals and one extra canal on the distal side. The working length was confirmed by radiograph [Fig. 3]. The dressing was done by Calcium hydroxide which acts as medicament and cavit (temporary cement) was used for closing the cavity. When teeth were asymptomatic, then lateral condensation method was used for obturation [Fig. 4]. Then the permanent restoration was done by composite resin (Dentsply SDR Flowable Bulk Filling Material) [Fig. 5]

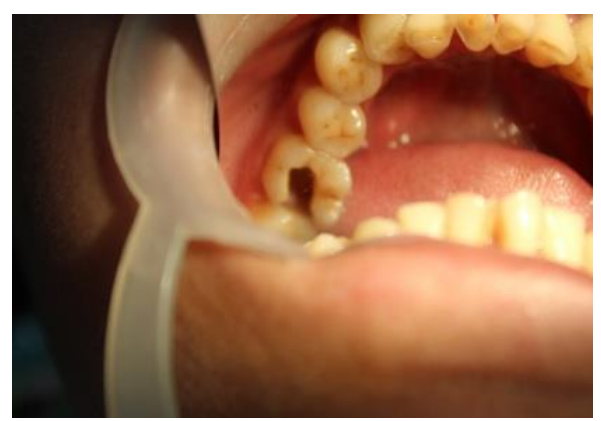

Fig. 1: Preop photograph

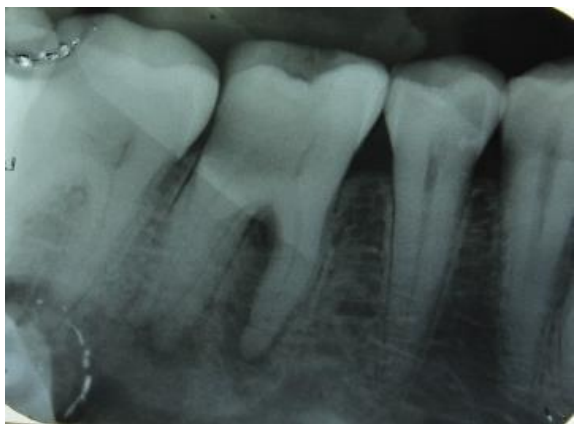

Fig. 2: Initial radiograph 


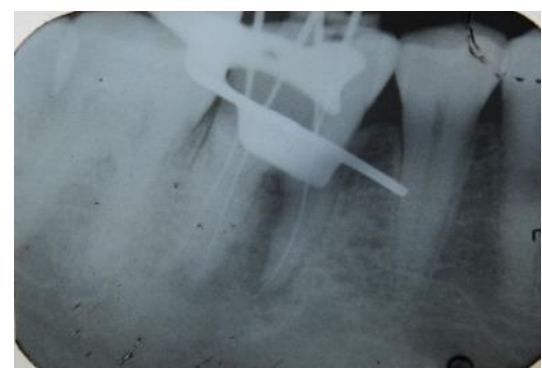

Fig. 3: Working length

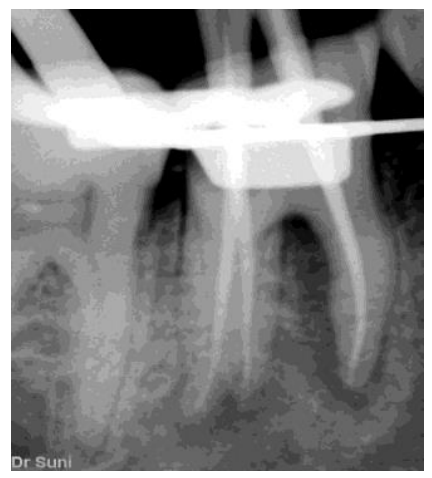

Fig. 4: Master cone

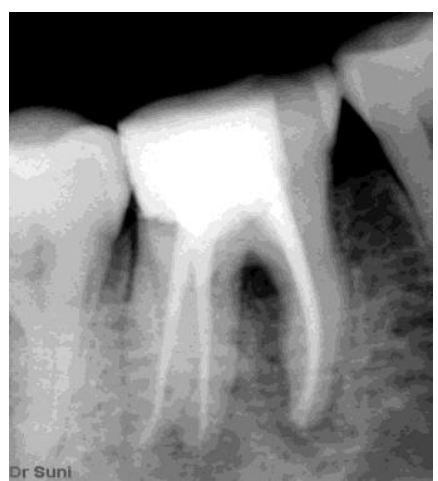

Fig. 5: Post operative radiograph

\section{Case 2}

A 20 years young male patient referred to the department with the chief complaint of food lodgement and pain in lower left back tooth region for 3 years. The pain was dull $\&$ intermittent in nature for 3 months. On intraoral examination of 36 revealed a deep interproximal caries and teeth are tender. Teeth are nonvital on vitality test. On the radiographic examination of 36 revealed a radiolucency which is covering the pulp chamber and periapical radiolucency are present around the mesial root [Fig. 6]. There are additional radiolucency outline is present in periodontal ligament around the distal root. This led to the probability of an extra canal distally. After examination, our diagnosis was the pulp necrosis with chronic apical periodontitis. Treatment in 36 was stared after the rubber dam isolation. Caries was removed and access opening was done by Endo access bur. An exploration of the access opening using DG16 four orifices is detected i.e., two distal canals and two mesial canals. The working length is taken by radiograph [Fig. 7]. Step-back technique is used for the preparation of the canal. For this procedure, K-files were used.

Irrigated was done by using $5.25 \%$ sodium hypochlorite and 17\% EDTA solutions. The dressing was done by Calcium hydroxide Avenue Avuecal (intracanal medicament) and closed by temporary cement. The tooth was asymptomatic after two week and master cones confirm by radiograph [Fig. 8], Obturation is done by lateral condensation method by AH plus sealer [Fig. $9 \&$ 10]. Then the final restoration was done and PFM crown is given. Patient recall for follow up after 1 and 3 months radiograph are taken [Fig. $11 \& 12$ ].

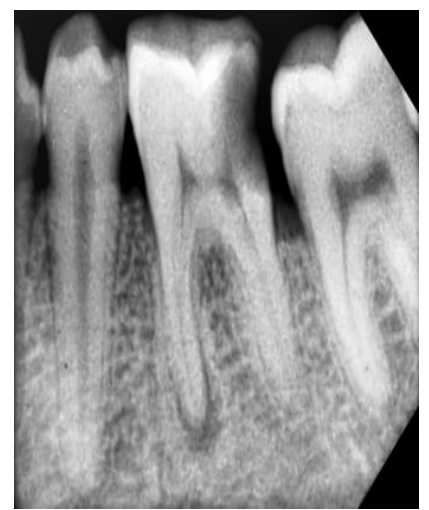

Fig. 6: Pre-operative radiograph

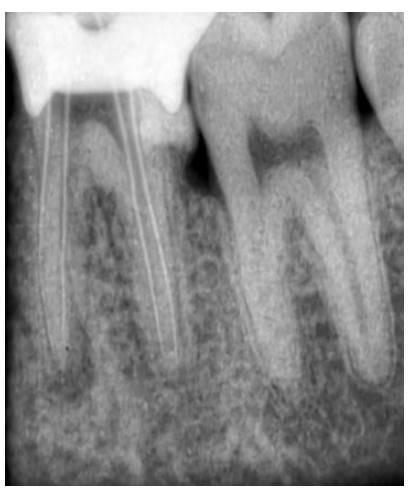

Fig. 7: Working length

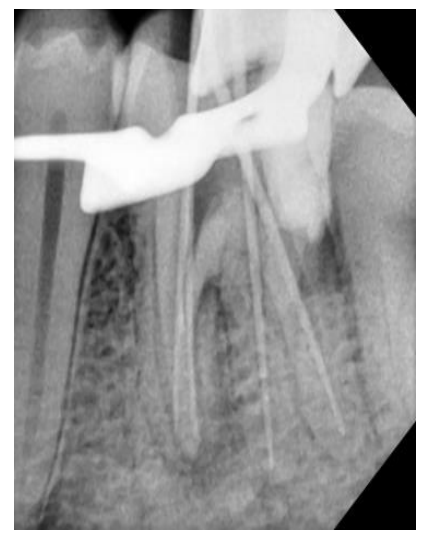

Fig. 8: Master cone radiograph 

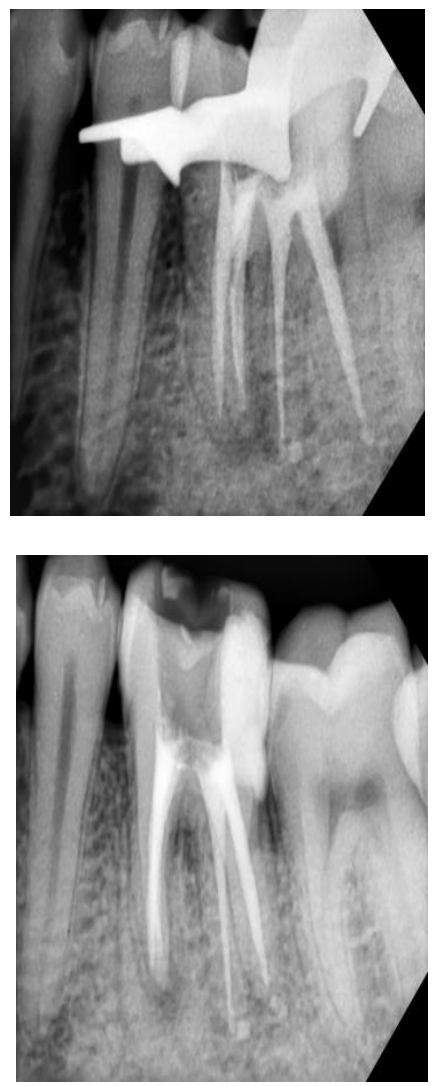

Fig. 9, 10: Obturation radiograph

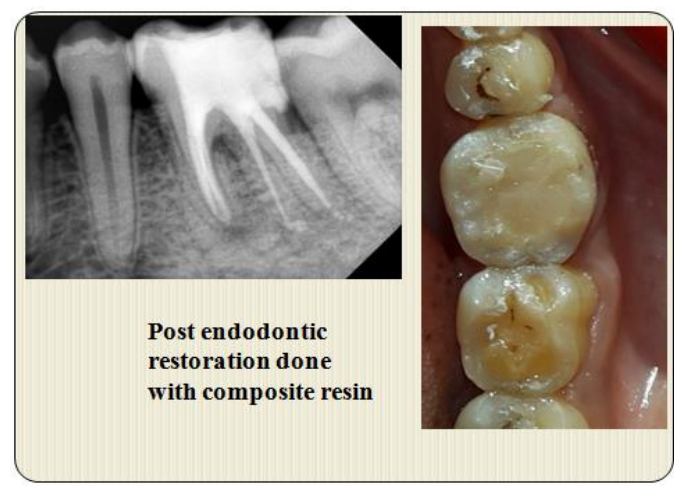

Fig. 11: Post Endodontic restoration done with composite resin

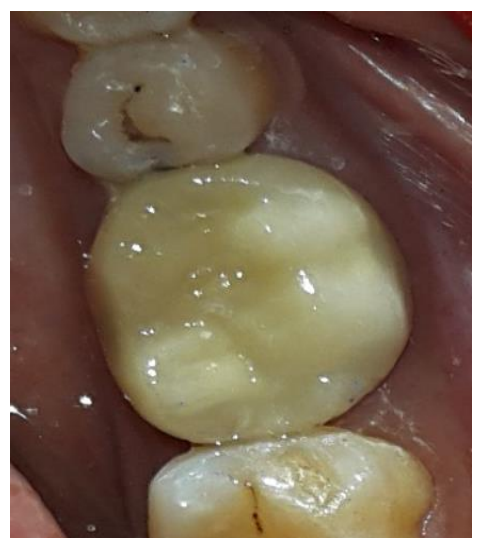

Fig. 12: Final fitted PFM crown

\section{Case 3}

A 25-year male patient was referred to the Department with complaining of slight pain on chewing in right lower back tooth. Clinical examination of teeth shown a carious lesion [Fig. 13] and it was tender on percussion. Right mandibular molar showed on the response when vitality test was done. Radiographic examination of 36 shown a radiolucency overlapping the pulp chamber and show of periapical radiolucency [Fig. 14]. Local anesthesia is performed. The tooth is isolated by a rubber dam and Caries was removed and access opening was done by Endo access bur. An exploration of the access opening using DG16 four orifices is detected i.e., two distal canal and two mesial canals [Fig. 15]. The working length of the canals is confirmed by radiograph [Fig. 16]. Shaping and cleaning were performed. The dressing is given by calcium hydroxide which acts as an intracanal medicament and access cavity was close by temporary cement. The teeth were asymptomatic after two week and master cones confirm by radiograph [Fig. $17 \& 18$ ], Obturation is done by lateral condensation method by AH plus sealer (epoxy resin, DENTSPLY). PFM crown is given.

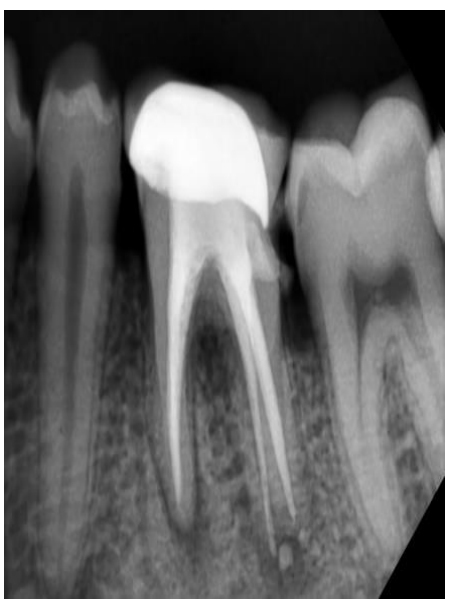

Fig. 13: After 1 months follow-up

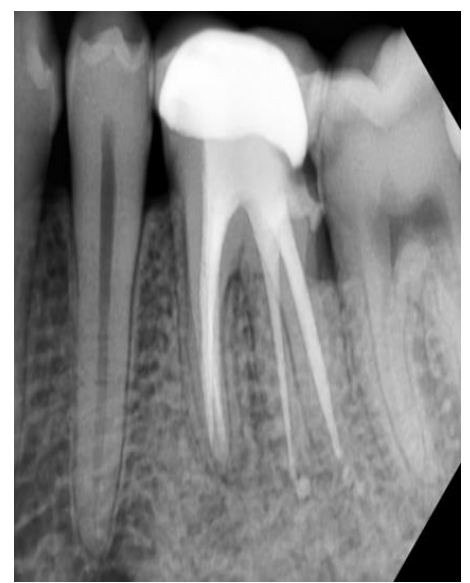

Fig.14: After 3 months follow-up 


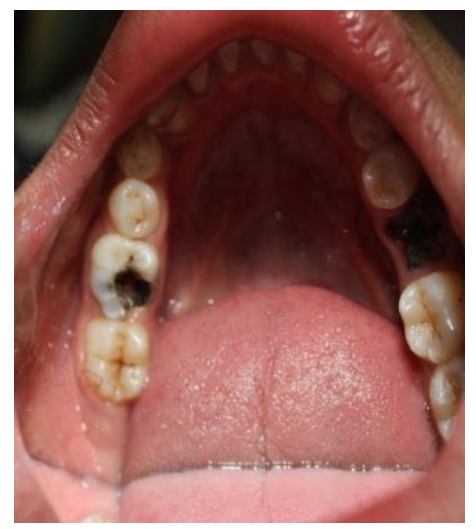

Fig. 15: Pre-operative photograph

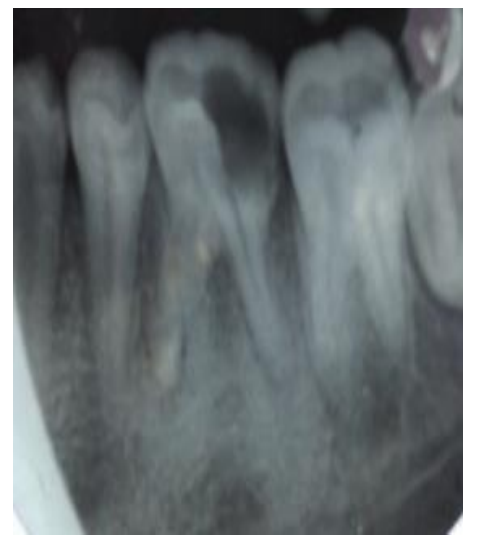

Fig. 16: Pre-operative radiograph

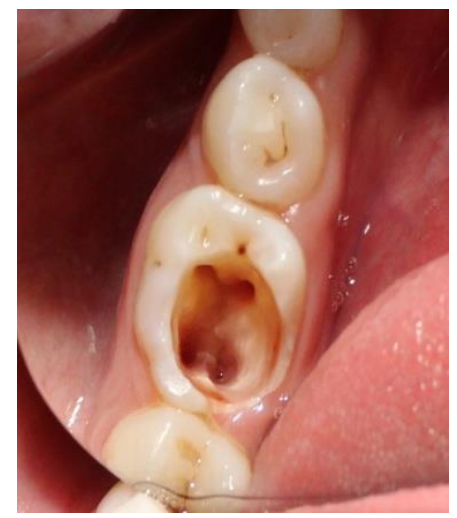

Fig. 17: Four Canals Orifices

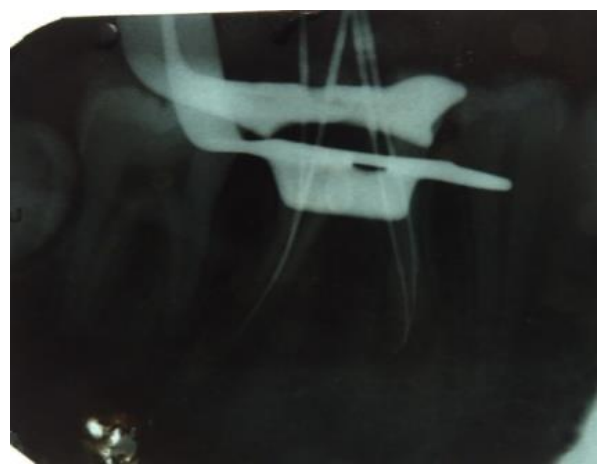

Fig.18: Working Length

\section{Discussion}

Mandibular first molar shown a prevalence of extra canals in the black population is $3 \%,{ }^{4}$ and less than $5 \%$ found in Caucasians and Indians population. ${ }^{5}$ The Prevalence of entomolaris is $5-30 \% .^{6}$ The etiology of occurrence of entomolaris is unknown. According to literature, it occurs due to external factors which influence the processes of odontogenesis and according to some literature, it may occur due to alteration of some specific genes or polygenic system(atavism). Racial genetic factors most commonly influence the specific gene which affected in the most prominent phenotypic manifestation. ${ }^{7,8}$ Radix entomolaris most commonly seen in mandibular first molar but mandibular second molar less commonly affected. ${ }^{9}$ According to Some literature occurrence of bilateral radix entomolaris is $50-67 \%$ cases. $^{10,11}$ The radix entomolaris varies in dimensions and varies short to normal length. Generally, the distal and mesiobuccal roots are longer than the extra root (radix entomolaris) and may be found partially fuse or separated. Correct tool is very necessary to locate the extra canal. So a tool for the identification of extra canals are magnifying glasses and microscopes ${ }^{12}$ and computed tomography. ${ }^{13}$

\section{Conclusion}

Always take consideration the presence of extra canal when treating mandibular molar. Human teeth anatomy may show racial variations so Clinician should have knowledge of the uncommon anatomy and morphology in the mandibular molars in the Indian population. The diagnosis of radix antamolarais can be made by angled preoperative radiograph and 3-D imaging. Chemo-mechanical preparation is necessary because extra root may show sever curvatures. Operating microscope are essential tool for identify the extra canal orifice.

Funding: No funding sources.

Conflict of interest: None declared.

\section{References}

1. Davini F, Cunha RS, Fontana CE, Silveira CF, Bueno CE. Radix entomolaris - A case report. RSBO 2012; 9(3):340- 44.

2. Calberson FL, Roeland J, De Moor RJ, Deroose CA. The Radix entomolaris and paramolaris: Clinical approach in Endodontics. J Endod 2007;33:58-63.

3. Carlsen O, Alexandersen V. Radix entomolaris: identification and morphology. Scan J Dent Res 1990;98:363-73.

4. Sperber GH, Moreau JL. Study of the number of roots and canals in Senegalese first permanent mandibular molars. Int Endod J 1998;31:112-16

5. Tratman EK. Three-rooted lower molars in man and their racial distribution. Br Dent J. 1938;64:264-74.

6. Walker T, Quakenbush LE. Three rooted lower first permanent molars in Hong Kong Chinese. Br Dent $J$ 1985;159:298-99. 
7. Reichart PA, Metah D. Three-rooted permanent mandibular first molars in the Thai. Community Dent Oral Epidemiol 1981;9:191-92.

8. Ribeiro FC, Consolaro A. Importancia clinica y antropologica de la raiz distolingual en los molars inferiores permanentes. Endodoncia 1997;15:72-8

9. Visser JB. Beitrag zur Kenntnis der menschlichen Zahnwurzelformen. Hilversum: Rotting; 1948:49-72.

10. Steelman R. Incidence of an accessory distal root on mandibular first permanent molars in Hispanic children. $J$ Dent Child 1986;53:122-23.

11. Yew SC, Chan K. A retrospective study of endodontically treated mandibular first molars in a Chinese population. $J$ Endod 1993;19:471-73.
12. .Feix LM, Boijink D, Ferreira R, Wagner RH, Barletta FB. Microscópio operatório na Endodontia: magnificação visual e luminosidade. RSBO 2010;7(3):340-48.

13. Abuabara A, Schreiber J, Baratto-Filho F, Cruz GV, Guerino L. Análise da anatomia externa no primeiro molar superior por meio da tomografia computadorizada cone beam. RSBO 2008;5(2):38-40.

How to cite the article: Baranwal H., Kumar N., Singh N., Singh A. Endodontic treatment of a mandibular first molar with radix entomolaris: A case series. Ann Prosthodont Restor Dent 2018;4(3):82-86. 